\title{
Correction to: "Ultrasonic nanocrystalline surface modification of low strength aluminum alloy: trade-off between surface integrity and production rate aiming at desired fatigue life"
}

\author{
Reza Bagherian Azhiri ${ }^{1} \cdot$ Aydin Jadidi $^{2}$. Abolfazl Salmani Bideskan ${ }^{2} \cdot$ Mostafa Rahimi Dizadji $^{3}$ \\ Published online: 21 February 2021 \\ (C) Springer-Verlag London Ltd., part of Springer Nature 2021
}

Correction to: The International Journal of Advanced Manufacturing Technology

https://doi.org/10.1007/s00170-021-06617-2

The original article contained a mistake.

Author name "Mostafa Rahimi Dizji" should be read as "Mostafa Rahimi Dizadji" as correctly shown above.

The original article has been corrected.

Publisher's note Springer Nature remains neutral with regard to jurisdictional claims in published maps and institutional affiliations.

The online version of the original article can be found at https://doi.org/ 10.1007/s00170-021-06617-2

Reza Bagherian Azhiri

Reza.azhiri@utdallas.edu

1 Department of Mechanical Engineering, University of Texas at Dallas, Dallas, TX, USA

2 Department of Mechanical Engineering, University of Tabriz, Tabriz, Iran

3 Department of Mechanical Engineering, University of Tehran, Tehran, Iran 